\title{
Finite Element ANALYsis of a StRENGTHENED BEAm Deliberating ELASTICALLY ISOTROPIC AND ORTHOTROPIC CFRP MATERIAL
}

\author{
K. Ghaedi ${ }^{1}$, Z. Ibrahim ${ }^{1}$, A. Javanmardi ${ }^{1}$, M. Jameel ${ }^{1}$, U. Hanif ${ }^{1}$, S. K. Rehman ${ }^{1}$ and M. Gordan ${ }^{1}$ \\ ${ }^{1}$ Department of Civil Engineering, University of Malaya, 50603, Kuala Lumpur, Malaysia \\ Date received: 09/03/18, Date accepted: 30/08/18 \\ Corresponding authors'email: khaledqhaedi@yahoo.com, zainah@um.edu.my,
}

\begin{abstract}
Using appropriate material properties for analyzing different models in academic and commercially available finite element software is one of the main concerns for design engineers and researchers. This paper demonstrates the importance of using appropriate material properties for the models to be considered by engineers during finite element modelling. Two reinforced concrete (RC) beams strengthened with Carbon Fiber Reinforced Polymer (CFRP) strips are investigated, considering the CFRP elements as elastically isotropic and orthotropic materials. To show the significance of the selective material properties, all properties of the models are chosen to be exactly the same for the two beams except for the CFRP strip. To validate the study, an RC beam is tested experimentally and the numerical results are compared to the experimental test. The results show that CFRP with isotropic or orthotropic properties has no significant influence on beam responses such as stresses, displacements and damage response under applied loadings.
\end{abstract}

Copyright (C) 2018 UNIMAS Publisher. This is an open access article distributed under the Creative Commons Attribution-NonCommercial-ShareAlike 4.0 International License which permits unrestricted use, distribution, and reproduction in any medium, provided the original work is properly cited.

Keywords: Isotropic materials, orthotropic materials, CFRP, adhesive, ABAQUS

\subsection{INTRODUCTION}

Concrete materials have recently been used in many projects as these materials have favorable behaviour in construction of civil structures [1-5]. Concrete may be modified to increase its capacity against applied load, particularly under flexural loading. In recent years, concrete with Carbon Fiber Reinforced Polymer (CFRP) has seen an increase in use to improve its characteristics [6-9]. A wide range of research has been accomplished through bending tests on reinforced concrete (RC) and on steel beams strengthened with CFRP [10-13]. The behavior of such concrete beams are now well agreedupon [8], and many stress-strain curve models have been projected for them using isotropic material properties. Besides, some researchers have used elastically orthotropic material for modeling such as Obaidat [11]. A model of isotropic linear elastic is frequently designed to model CFRP and Fiber Reinforced Polymer (FRP) where the trend of those materials is corresponding to the principal stresses [14]. Also, orthotropic linear elastic behavior can be considered since CFRP and FRP principally have orthotropic behavior [15]. Therefore, there is a challenge to use elastic material properties in terms of isotropic or orthotropic for materials like FRP or CFRP. This paper attempts to investigate the behavior of a strengthened RC beam with CFRP modeled with isotropic and orthotropic material properties in order to inspect the effect of elasticity behavior on overall response of the concrete beam-like structures under certain static loading.

\subsection{METHODOLOGY}

The geometry of the concrete beam is $250 \times 125 \times 3000 \mathrm{~mm}$. The CFRP is attached to the RC beam using adhesive with the same width and length of the CFRP; namely $125 \mathrm{~mm}$ and $2900 \mathrm{~mm}$. A thickness of $1 \mathrm{~mm}$ and $0.17 \mathrm{~mm}$ is used for CFRP and adhesive materials, respectively. The finite element discretization of the model is done by means of the commercial software package ABAQUS 6.14.2. This package has the ability to simulate the real response of different structures having wide range of different material properties [16-19]. 
In this study, the concrete beam is designed with 8-node linear brick element with hourglass control and reduced integration or C3D8R. For steel bars a 2-node linear 3D truss (T3D2) is used. The layer of adhesive is modeled by means of a 3D cohesive element (COH3D8). The adhesive, CFRP and the RC beam are attached using tie constraints. The cohesive law is adopted to define the constitutive model. The CFRP is modeled once as an isotropic material and then as an orthotropic material. For the orthotropic materials the following characteristics are assigned [11]:

$\mathrm{E}_{11}=165 \mathrm{GPa}$.

$\mathrm{V}_{12}=\mathrm{V}_{13}=0.3$

$\mathrm{E} 22=\mathrm{E} 33=9.65 \mathrm{GPa}$.

$\mathrm{G} 12=\mathrm{G} 13=5.2 \mathrm{GPa}$.

$\mathrm{V} 23=0.45$

$\mathrm{G} 23=3.4 \mathrm{GPa}$.

Where E, V and G are module of elasticity, Poisson's ratio and shear modulus of the materials, respectively. The subscript 1,2 and 3 denotes the $\mathrm{x}, \mathrm{y}$ and $\mathrm{z}$ direction.

Table 1 indicates the elastic modulus and yield stress of the materials used in modeling of the RC beam. For adhesive, shear modulus of $4 \mathrm{GPa}$, Poisson's ratio of 0.38 and thickness of $0.17 \mathrm{~mm}$ are used. The geometry and Finite Element (FE) model of the strengthened RC beam are depicted in Figure 1 and 2, respectively. A study on mesh convergence has been carried out to achieve a suitable mesh in order to study its finite element model. To implement an appropriate mesh in order to run and converge the analysis, several FE meshes have been created.

8608 elements and 12018 nodes are used for discretization of different parts of the model based on the consequences attained from the testing of 8326, 7450, 9654, 8608 and 6442 elements.

The whole FE model of the sections needs to be considered due to asymmetric boundary conditions (hinge and roller support at each side of the RC beam).

Table 1 Material properties of concrete beam, CFRP, adhesives and steel bars

\begin{tabular}{lcc}
\hline & Elastic Modulus E $(\mathrm{GPa})$ & Yield Stress $(\mathrm{MPa})$ \\
\cline { 2 - 3 } Concrete Beam & 21 & 40 \\
CFRP & 165 & 1300 \\
Stirrup & 200 & 340 \\
Longitudinal Bar & 200 & 400 \\
\hline
\end{tabular}




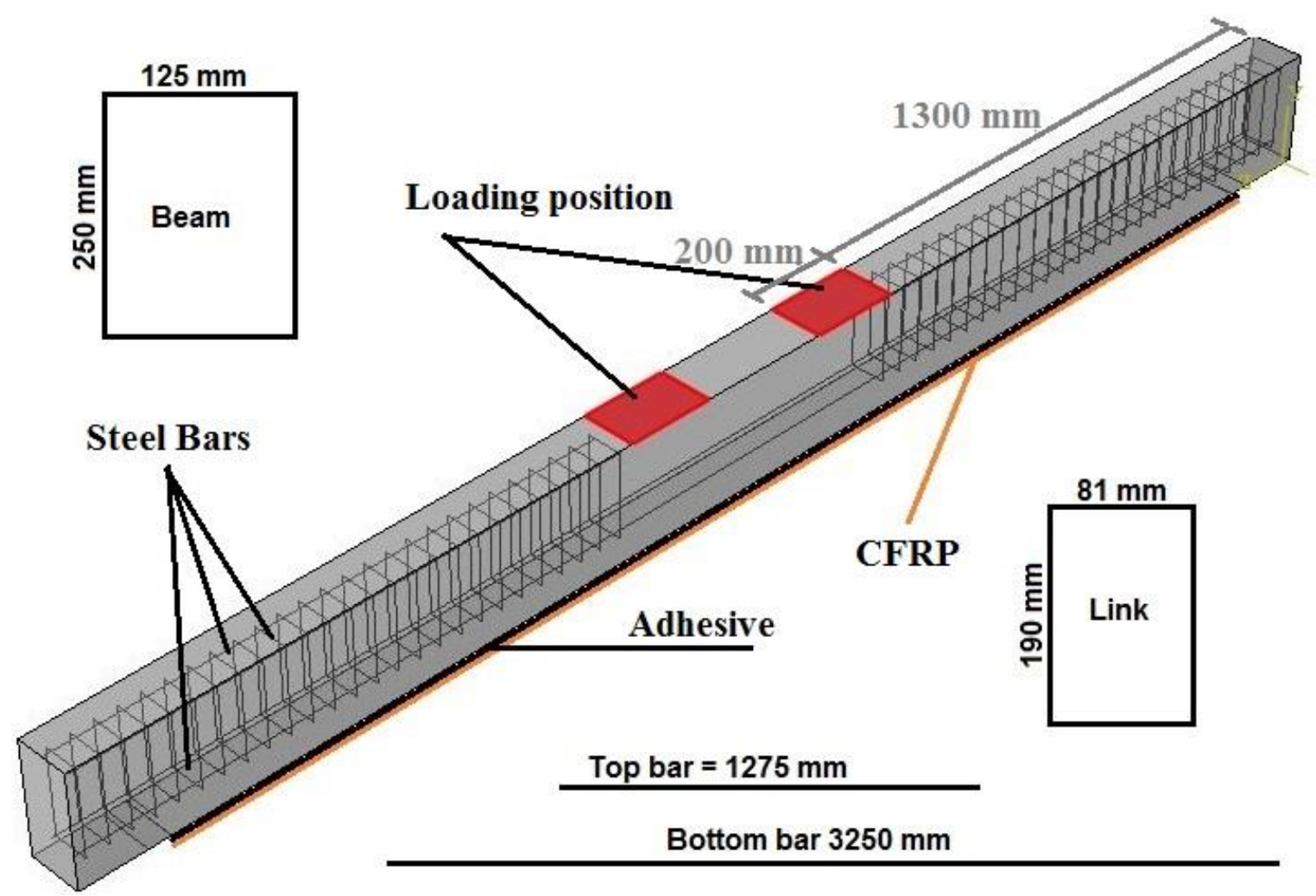

Figure 1 Geometry of the RC beam

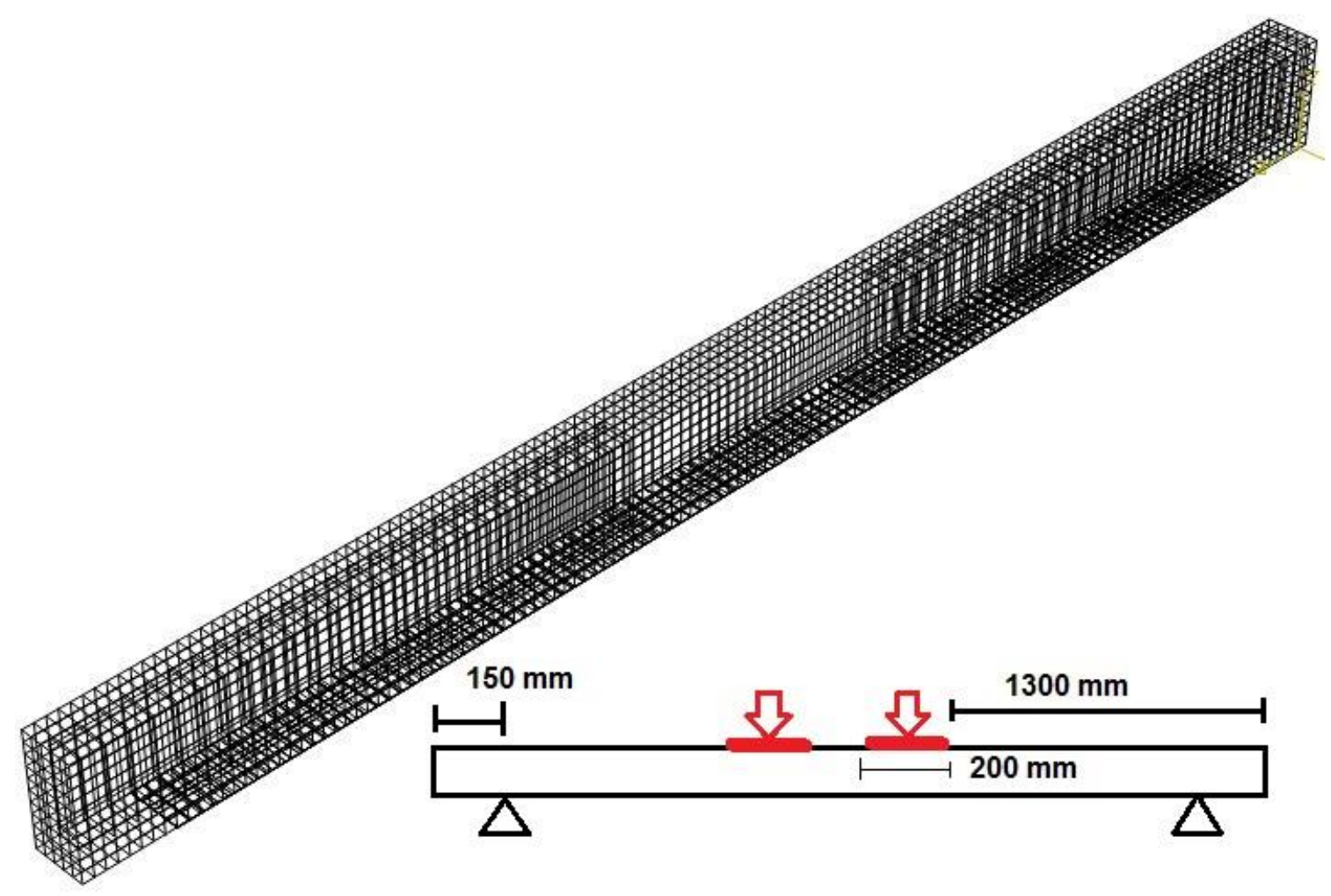

Figure 2 Transparent view of FE modeling of the whole model with load position and boundary conditions 
The procedure of the current study is drawn and presented in Figure 3.

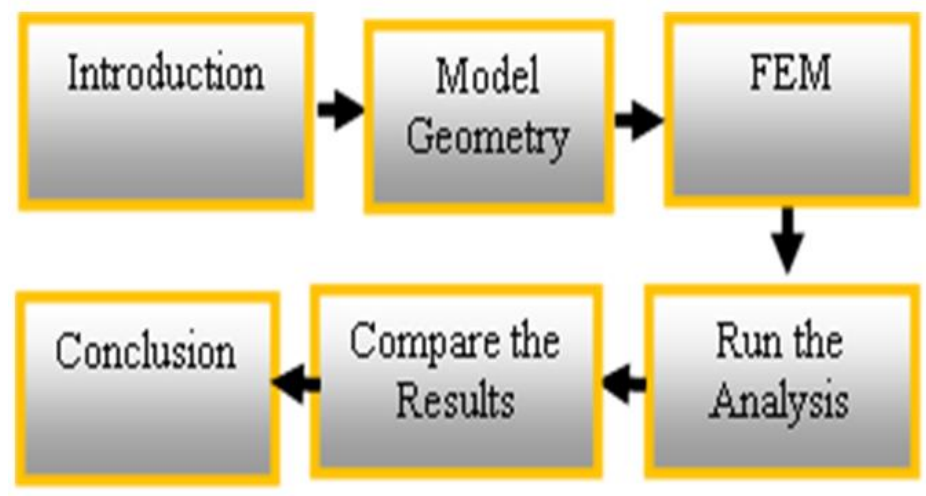

Figure 3 Diagram of the modelling processes

\subsection{EXPERIMENTAL VALIDATION OF THE MODEL}

The correctness of the present model is tested by experiment. As illustrated in Figure 4 (a), a strip of CFRP was attached to the bottom of the studied RC beam to evaluate the resistance effect of CFRP material on the RC beam under flexural load. A uniform incremental static load was applied to the test specimen up to its failure level (cracking stage). This can be seen in Figure 4(b). According to the developed FE method above, the strengthened RC beam with CFRP strip was simulated under the same conditions using ABAQUS software. Both isotropic elasticity and orthotropic behaviour of the CFRP were considered in FE analysis. A comparison of the experimental and software-based results are presented in the results and discussion.

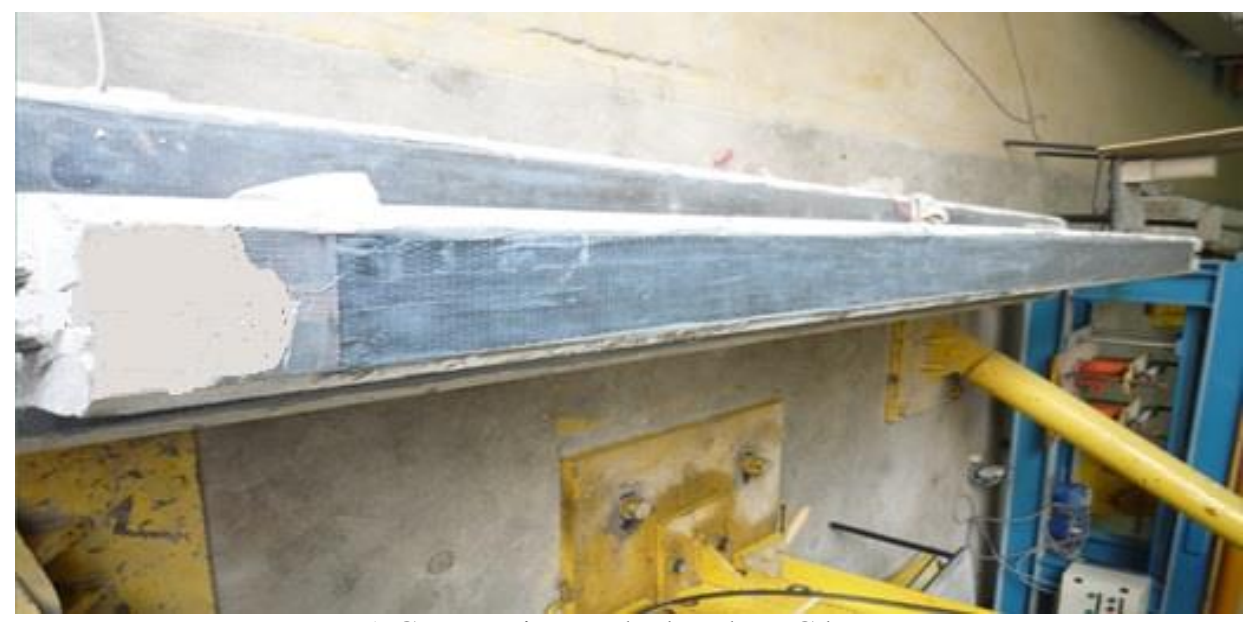

a) CFRP strip attached to the RC beam 


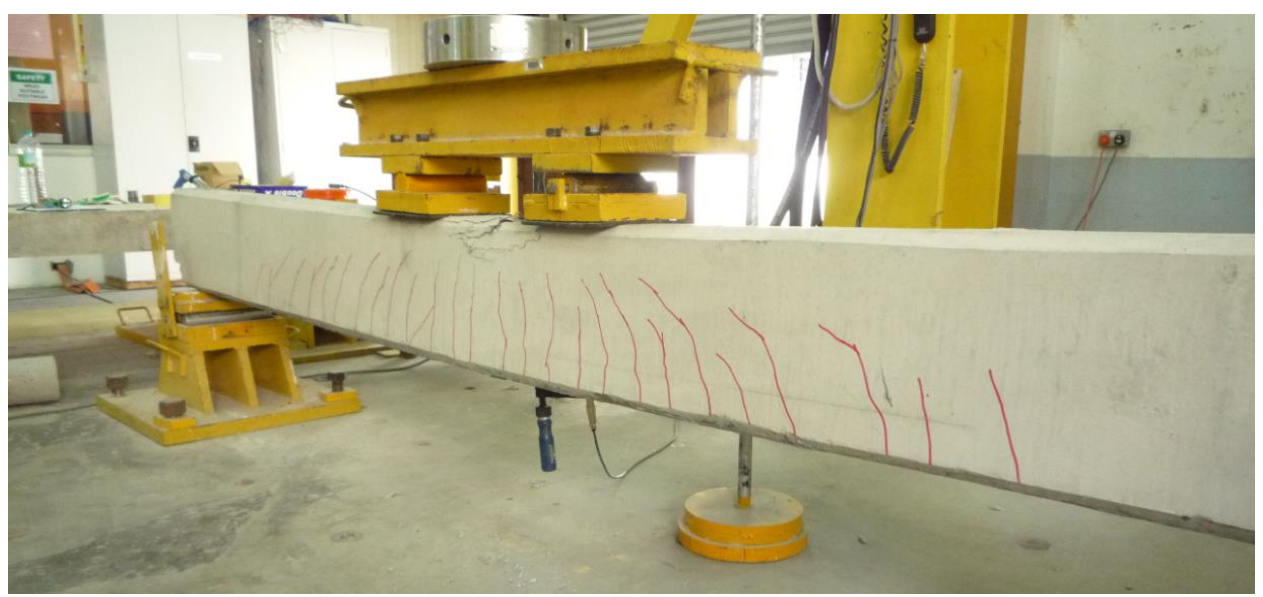

b) Strengthened RC beam under bending test

Figure 4 The RC beam specimen a) strengthened with CFRP material under b) flexural loading

\subsection{CONCRETE DAMAGED PLASTICITY (CDP)}

One of the main important responses of structural members in analysis and design is damage severity [20-24]. In order to explain the complicated mechanical response of the concrete materials under loading, many constitutive approaches have been proposed including damage model, anisotropic damage and isotropic damage model. The method of explaining the nonlinear behavior of each combinatorial material in a multiphase composite material is generally used in the cracking analysis for concrete materials. This model factorizes the uniaxial strength functions into two divisions to stand for the permanent degradation of stiffness and deformation. The model assumes two major failure mechanisms for concrete materials, the first for cracking and the second one for crushing in tension and compression, respectively.

In the incremental theory of plasticity the strain tensor ${ }^{\varepsilon}$ ) is divided into two parts including the elastic strain $\left(\varepsilon^{E}\right)$ and plastic strain $\left(\varepsilon^{p}\right)$ where the linear elasticity can be written as:

$$
\varepsilon=\varepsilon^{e}+\varepsilon^{p}
$$

The variables $\left\{\varepsilon^{e}{ }_{,} \varepsilon^{p}, \kappa\right\}$ are assumed to be identified at time (t). With that information, for stress tensor the following can be obtained:

$$
\sigma=(1-d) \bar{\sigma}=(1-d) E_{0}\left(\varepsilon-\varepsilon^{p}\right) \text { and } d=d(\kappa)
$$

Where ${ }^{d}$ is the scalar stiffness degradation variable which can be in the range of 0 (undamaged) to 1 (fully damaged); $E_{0}$ is the undamaged elastic stiffness for concrete material. The failure mechanism of the material associated with the damage reduces the elastic stiffness. This stiffness is assumed as a function of the internal variable $(\kappa)$ including of the compressive and tensile variables, namely $\kappa=\left(\kappa_{t}, \kappa_{c}\right)$. The function of damages consisting of tension $\left(d_{t}\right)$ and compression $\left(d_{c}\right)$ are nonlinear functions which are computed by uniaxial response in tension and compression using practical data. Hence, the effective stress is determined as:

$$
\bar{\sigma}=\frac{\sigma}{1-d}=E_{0}\left(\varepsilon-\varepsilon^{p}\right)
$$

\subsection{RESULTS AND DISCUSSION}

\subsection{STRESS}

The von Mises stresses of the strengthened RC beam owing to use of isotropic and orthotropic material 
properties are indicated in Figure 5. As shown in this figure, the difference in stress response between both models is negligible. The maximum von Mises stress when the isotropic and orthotropic properties are used for CFRP is $44.57 \mathrm{MPa}$ and $45.42 \mathrm{MPa}$ respectively, with approximately $2 \%$ difference. In addition to this, the stress contour of the RC beam for the different material properties of CFRP is extremely close to each other.

Analogous to RC beam stress response, the von Mises stress of CFRP considering utilized isotropic and orthotropic material is shown in Figure 6. Figure 6(b) remarkably shows the stress direction in the CFRP plate when orthotropic elastic model is implemented. Nevertheless, for this condition the percentage of variance of the stress is around $75 \%$ smaller than the isotropic model but it does not change the overall response of the RC beam at the end of analysis. As shown in Figure 6(b), since the orthotropic material is assigned to CFRP in principal direction, therefore the stress response can obviously be seen in that direction.

\subsection{DISPLACEMENT}

The displacement response of the RC beam for two different analyses is demonstrated in Figure 7. From this figure it can be concluded that, similar to stress response, the difference of displacement for the two models can be ignored. These values are $1.847 \mathrm{~mm}$ and $1.9 \mathrm{~mm}$ respectively with about $3 \%$ difference.
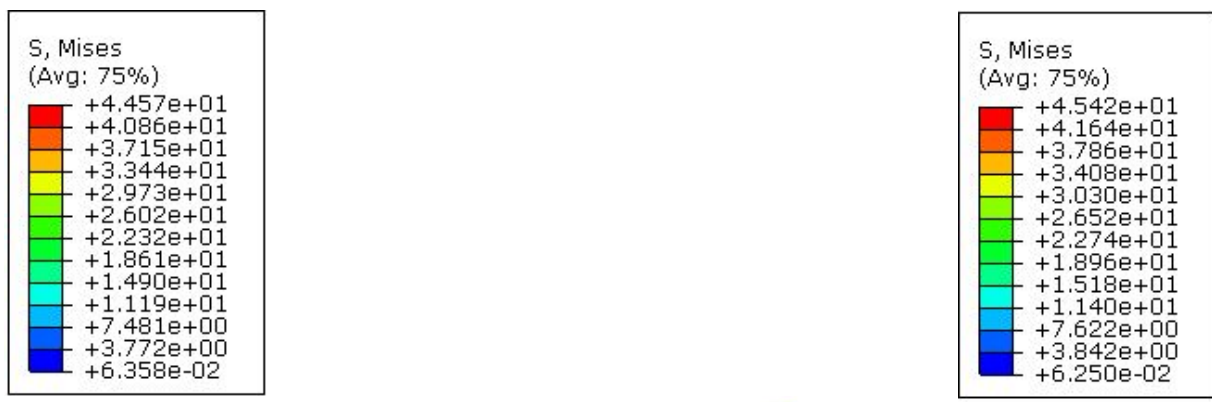

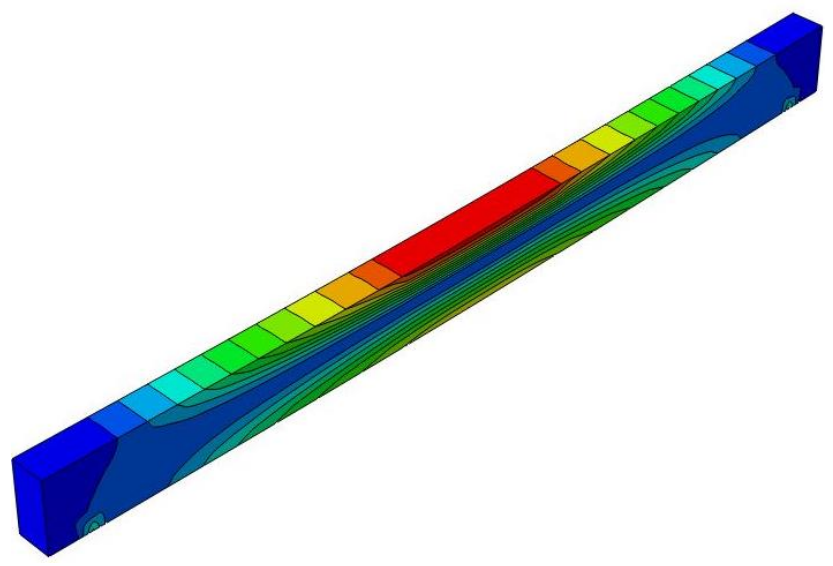

a) Isotropic CFRP

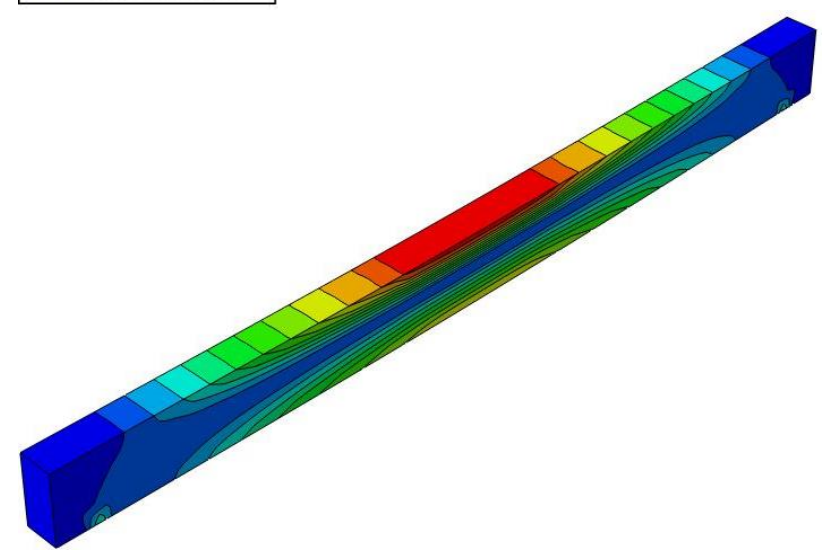

b) Orthotropic CFRP

Figure 5 Von Mises Stress of the RC beam for different material properties used for CFRP 

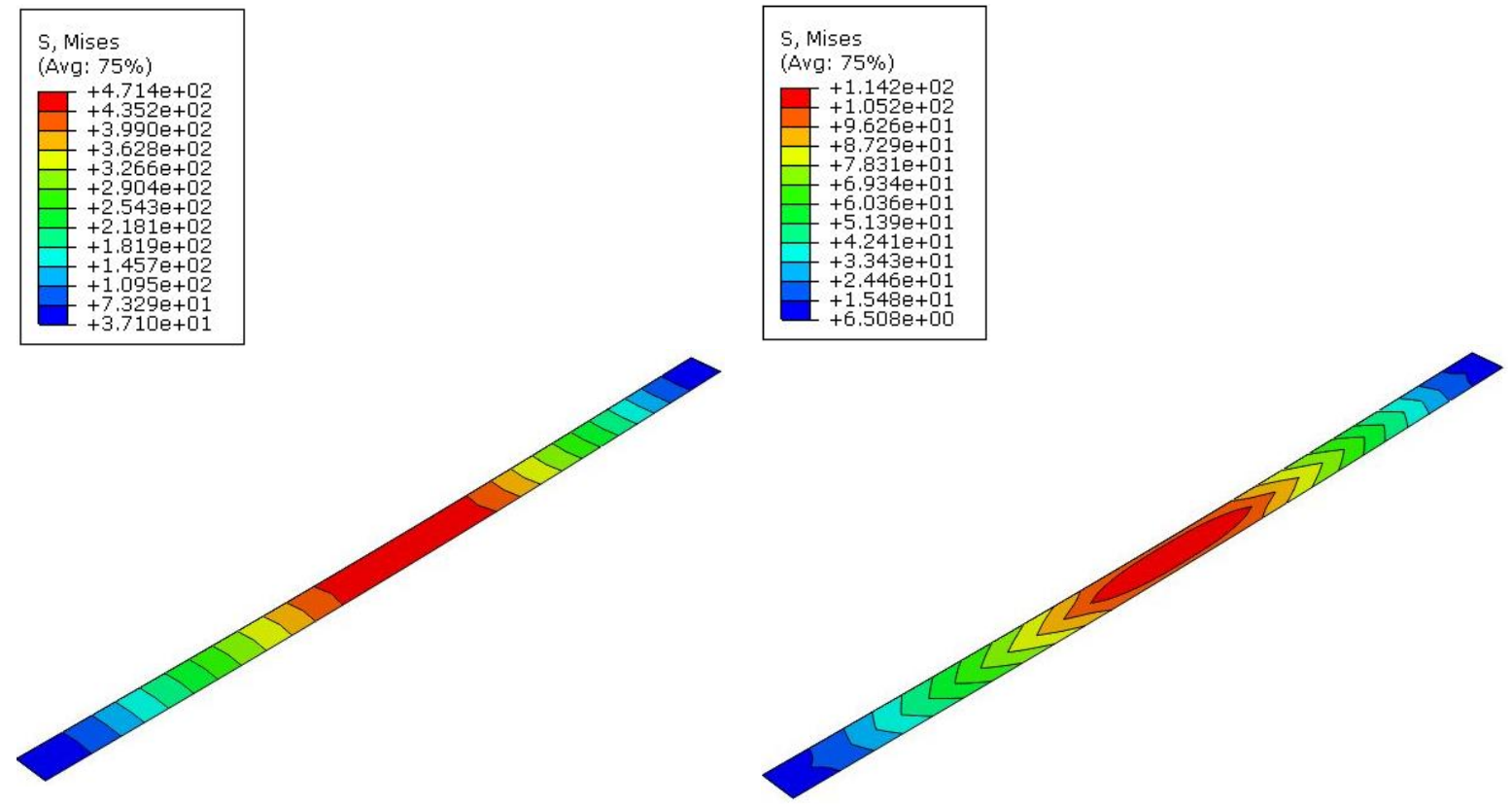

a) Isotropic CFRP

b) Orthotropic CFRP

Figure 6 Von Mises Stress of the CFRP for different used material properties

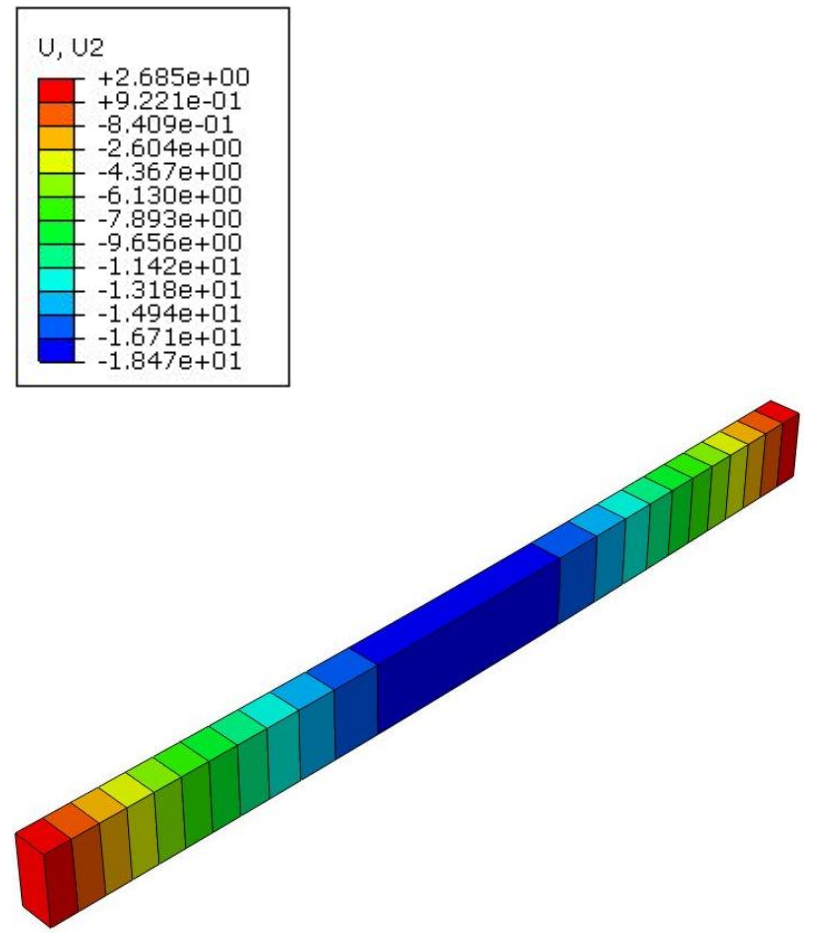

a) Isotropic CFRP
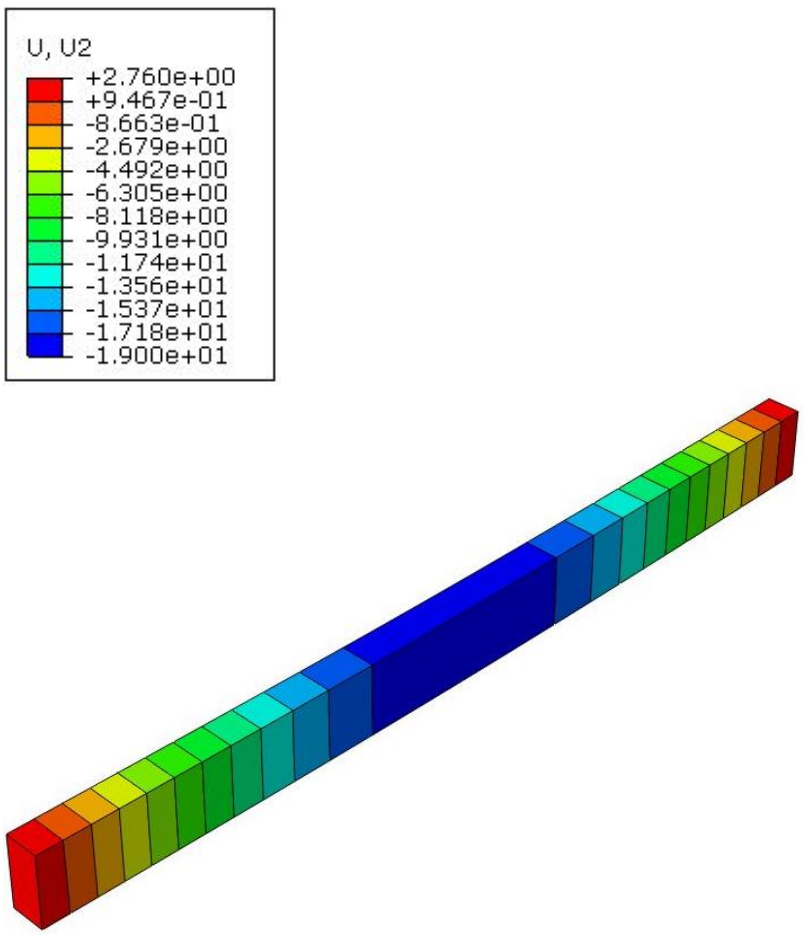

b) Orthotropic CFRP

Figure 7 Displacement of the RC beam for different material properties used for CFRP

\subsection{LOAD-DEFLECTION AND STRESS-STRAIN CURVES}

The force-displacement curve for both isotropic and orthotropic elastic models are compared with the experimental test and presented in Figure 8(a). The FE model presents accurate expectation for the models. As observed in the figure, the values and trends of the force-displacement curves for both cases 
are notably near to the result obtained in experiment. The force-displacement relation is $123.257 \mathrm{KN}$ $17.74 \mathrm{~mm}$ for the isotropic and $123.254 \mathrm{KN}-18.24 \mathrm{~mm}$ for the orthotropic model. Comparison of values in terms of force and displacement through this figure show a proportion of $2.4 \mathrm{e}-3 \%$ and $2.8 \%$ in changes, respectively.

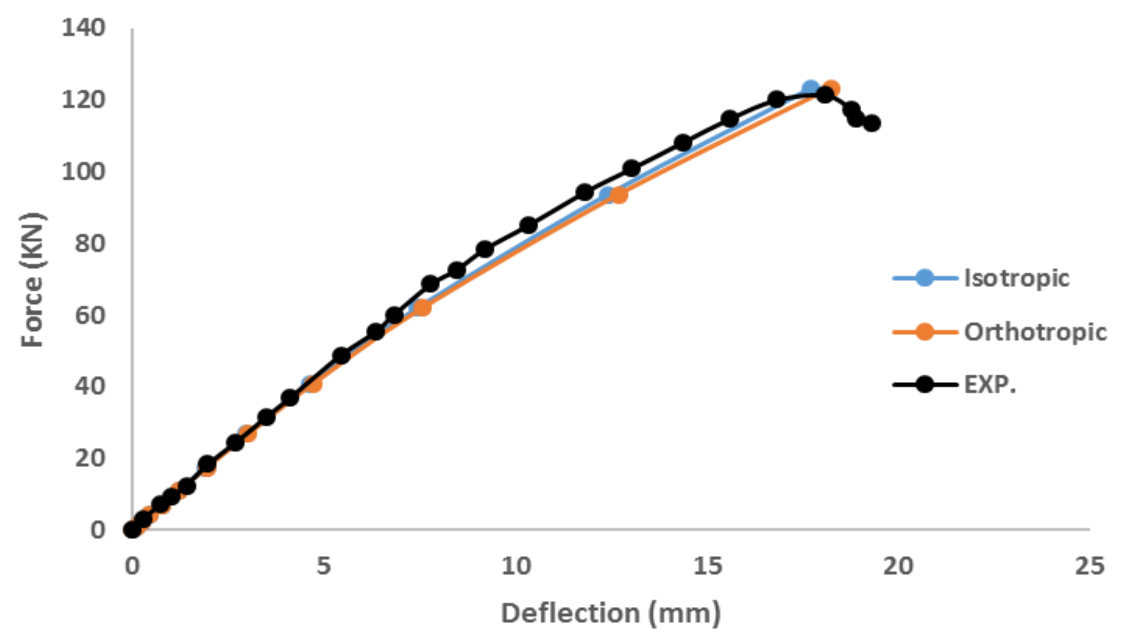

a) Force-displacement curves

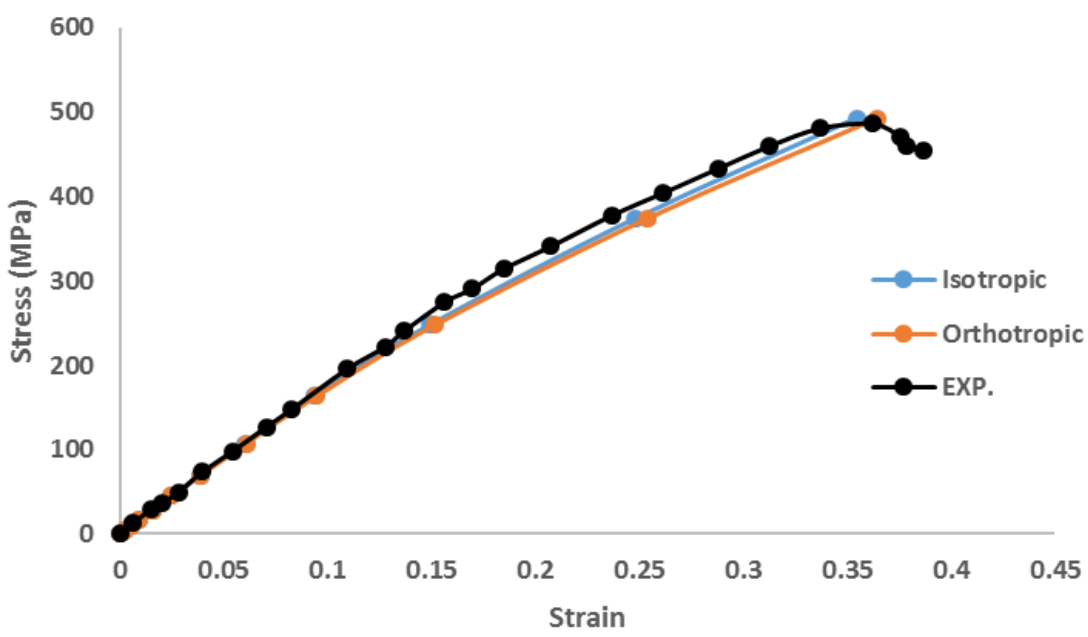

b) Stress-strain curves

Figure 8 Comparison of a) force-displacement and b) stress-strain relationship curve

The stress-strain relationship curve of the model is compared to the experiment as shown in Figure 8(b). Since the stress-strain has a direct relationship with load-deflection curve, a similar curve or performance is achieved. As a result of this, a simillar percentage of difference obtained for loaddeflection result can be observed for stress-strain curve considering the effect of isotropic and orthotropic elastic models .

\subsection{DAMAGE RESPONSE}

Based on the uniqueness of the cracking development, the damage propagation is inspected considering the effect of isotropic and orthotropic behavior of CFRP. The starting point of the cracking is formed from the central elements at the bottom of the RC beam and it propagates toward both sides. The tensile damage response of the $\mathrm{RC}$ beam in both cases is shown in Figure 9. Comparison of these results with those obtained from experiment (see Figure 4) confirms the accuracy of the study once again. As can be observed from the damage response, the RC beam strength modeled with isotropic and orthotropic 
behavior of CFRP material has a very close response. Thus, it is emphasized that modeling of CFRP can be simplified from an orthotropic to an isotropic method.

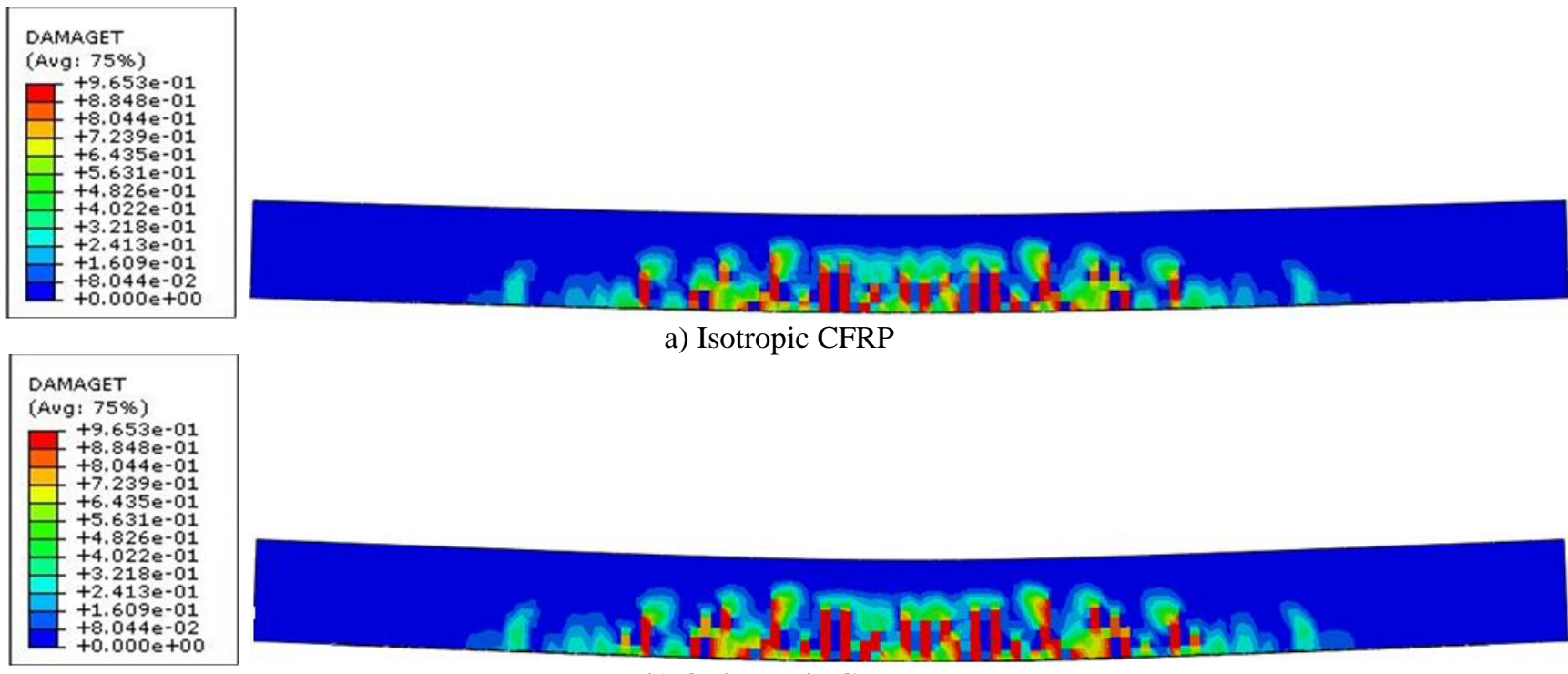

b) Orthotropic CFRP

Figure 9 Damage response of the RC beam considering a) isotropic material and b) orthotropic material of CFRP

\subsection{CONCLUSIONS}

Elastic isotropic and orthotropic behaviors were used to characterize the CFRP used for strengthening of a RC beam under flexural test. A cohesive model was designed to address an interface material between concrete and CFRP and analzyed using ABAQUS software. An experimental test was then carried out in the lab to validate the FE analysis results. Based on the experiment and modeling analysis, the following conclusions are drawn:

- The overall responses of the RC beam such as stresses, displacements and damage response are not much different when isotropic and orthotropic material properties are defined for CFRP plate.

- The variance of load-displacement curves as well as stress-strain relationship for the RC beam can be ignored when orthotropic material properties are deliberated for CFRP compared to that conducted isotropic features.

- Finally, it is not obligatory to take orthotropic elastic material properties of the unidirectional CFRP into consideration. A uniaxial CFRP basically has an orthotropic behavior; nonetheless simulations illustrated that where the direction of principal stress corresponds with the fiber direction, an isotropic material could be replaced with a fine and acceptable accuracy.

\section{ACKNOWLEDGEMENT}

The authors gratefully acknowledge financial support from the Fundamental Research Grant Scheme, Ministry of Education, Malaysia (FRGS - Project No. FP004-2014B), Postgraduate Research Grant (PPP-Project No. PG177-2016A) and University of Malaya Research Grant (UMRG-Project No. RP004A-13AET). 


\section{REFERENCES}

[1] Ghaedi K, Hejazi F, Ibrahim Z, Khanzaei P (2017). Flexible foundation effect on seismic analysis of Roller Compacted Concrete (RCC) dams using finite element method. KSCE Journal of Civil Engineering, 22(4), 12751287.

[2] Ghaedi K, Javanmardi A, Gordan M, et al (2015). Application of 2d and 3d finite element modelling of gravity dams. In: The 3rd National Graduate Conference (NatGrad2015), Universiti Tenaga Nasional, Putrajaya Campus. $8-9$

[3] Ghaedi K, Jameel M, Ibrahim Z, Khanzaei P (2016). Seismic analysis of Roller Compacted Concrete (RCC) dams considering effect of sizes and shapes of galleries. KSCE Journal of Civil Engineering, 20(1), 261-272.

[4] Khanzaei P, Abdulrazeg A a., Samali B, Ghaedi K (2015). Thermal and Structural Response of RCC Dams During Their Service Life. Journal of Therm Stress, 38(6), 591-609.

[5] Hanif MU, Ibrahim Z, Jameel M, et al (2016). A new approach to estimate damage in concrete beams using nonlinearity. Construction and Building Materials, 124(6), 1081-1089.

[6] Almassri B, Mahmoud FAL, Francois R (2015). Behaviour of corroded Reinforced Concrete beams repaired with NSM CFRP rods, Experimental and Finite Element Study. Composites Part B: Engineering. 92, 477-488.

[7] Kang J, Park Y, Park J, et al (2005). Analytical Evaluation of RC Beams Strengthened with Near Surface Mounted CFRP Laminates. International Concrete Abstracts Portal, 230, 779-794.

[8] Hawileh RA (2012). Nonlinear finite element modeling of RC beams strengthened with NSM FRP rods. Construction and Building Materials. 27(1), 461-471.

[9] Yu T, Teng JG (2010). Finite element modeling of confined concrete- I : Drucker - Prager type plasticity model. Engineering Structures. 32(3), 665-679.

[10] Kaya M, Arslan AS (2009). Analytical modeling of post-tensioned precast beam-to-column connections. Materials \& Design, 30(9), 3802-3811.

[11] Obaidat YT, Heydena S, Dahlbloma O, Abu-Farsakhb G, Abdel-Jawad Y (2011). Retrofitting of reinforced concrete beams using composite laminates. Construction and Building Materials, 25(2), 591-597.

[12] Narmashiri K, Sulong NHR, Zamin M (2012). Failure analysis and structural behaviour of CFRP strengthened steel I-beams. Construction and Building Materials. 30,1-9.

[13] Ghafoori E, Motavalli M (2015). Lateral-torsional buckling of steel I-beams retrofitted by bonded and un-bonded CFRP laminates with different pre-stress levels: Experimental and numerical study. Construction and Building Materials, 76,194-206.

[14] Fernando D (2012). Finite element analysis of debonding failures in CFRP-strengthened rectangular steel tubes subjected to an end bearing load. In: 6th International Conference on FRP Composites in Civil Engineering, pp 1-8

[15] Heshmati M, Haghani R, Al-emrani M (2014). Design of FRP / steel Joints Bonded by Thick Adhesive Layers Experimental charachterization and numerical modelling using damage mechanics. In: The Second International Conference on Advances in Civil and Structural Engineering, CSE 2, At Kuala Lumpur, Malaysia. pp 2-6

[16] Teng JG, Huang YL, Lam L YL (2007). Theoretical model for fiber reinforced polymer-confined concrete. Journal of Composites for Construction, 11(2), 201-10.

[17] Camata, G., Spacone, E. and Zarnic R (2007). Experimental and nonlinear finite element studies of RC beams strengthened with FRP plates. Composites Part B: Engineering, 38(2), 277-288

[18] Hu, H.T., Lin, F.-M. and Jan YY (2006). Nonlinear finite element analysis of reinforced concrete beams strengthened by fiber-reinforced plastics. Composite Structures, 63(3-4), 271-281.

[19] Ghaedi K, Jameel M, Ibrahim Z, Khanzaei P (2016). Seismic analysis of roller compacted concrete (RCC) dams considering effect of sizes and shapes of galleries. KSCE Journal of Civil Engineering, 20(1), 261-272.

[20] Javanmardi A, Ibrahim Z, Ghaedi K, et al (2018). Seismic isolation retrofitting solution for an existing steel cablestayed bridge. PLoS One 13:e0200482.

[21] Ghaedi K, Ibrahim Z, Jameel M, et al (2018). Seismic Response Analysis of Fully Base-Isolated Adjacent Buildings with Segregated Foundations. Advances in Civil Engineering, 2018, 1-21.

[22] Hanif MU, Ibrahim Z, Ghaedi K, et al (2018). Finite Element Simulation of Damage In RC Beams. Journal of Civil Engineering, Science and Technology, 9(1), 50-57.

[23] Ghaedi K, Ibrahim Z, Adeli H, Javanmardi A (2017). Invited Review: Recent developments in vibration control of building and bridge structures. Journal of Vibroengineering, 19(5), 3564-3580.

[24] Gordan M, Razak HA, Z. Ismail, Ghaedi K (2017). Recent developments in damage identification of structures using data mining. Latin American Journal of Solids and Structures, 14(13), 2373-2401. 